\title{
Susceptibility of Haemophilus ducreyi to spectinomycin in vitro
}

\author{
S HAFIZ,* B M JONES,* G R KINGHORN† AND B I DUERDEN* \\ From the *Department of Medical Microbiology, University of Sheffield Medical School, and the $\dagger$ Depart- \\ ment of Genitourinary Medicine, Royal Hallamshire Hospital, Sheffield
}

SUMMARY Using an agar dilution technique with standardised inocula prepared by ultrasonication, the minimum inhibitory concentrations (MICs) of spectinomycin were determined for 66 strains of Haemophilus ducreyi, eight of which were $\beta$ lactamase producers. All strains were sensitive to concentrations of spectinomycin, which were well within the therapeutic ranges attained with normal dosage. The $\mathrm{MIC}_{50}$ and $\mathrm{MIC}_{90}$ were $8 \mathrm{mg} / \mathrm{l}$, (range 0.007-16 mg $/$ ).

\section{Introduction}

Previous studies of the antimicrobial sensitivity of Haemophilus ducreyi, which causes classical chancroid and also contributes to other forms of genital ulcerations, have shown varied results, particularly with aminogyclosides and $\beta$ lactam antibiotics. ${ }^{1}$ Sng $e t$ $a l^{2}$ found that all 17 strains studied were sensitive to streptomycin, but Sturm and Zanen ${ }^{3}$ reported that 11 of 19 strains of $H$ ducreyi were resistant to aminoglycosides. In a separate study in this department we found that all 36 strains tested were sensitive to gentamicin, tobramycin, and amikacin (unpublished data). Aminoglycosides have been widely used to treat cases of chancroid caused by $\beta$ lactam resistant strains. Asin ${ }^{4}$ found that ulcers often relapsed and buboes progressed to suppuration during treatment with streptomycin, but both $\mathrm{Marmar}^{5}$ and $\mathrm{Hart}^{6}$ reported successful treatment with kanamycin of patients who had failed to respond to sulphonamide and tetracycline. Luders et al, ${ }^{7}$ Bardasch ${ }^{8}$ and Morel et $a l^{9}$ each obtained successful results with streptomycin, kanamycin, or gentamicin. Rajan and Sng, ${ }^{10}$ however, observed that in Singapore $52 \%$ of chancroid cases treated with either streptomycin or kanamycin failed to respond, whereas before 1980 excellent results with

Address for reprints: Mr B M Jones, Department of Medical Microbiology, University Medical School, Sheffield S10 2RX either drug had invariably been obtained. They suggested that the increased use of aminoglycosides to treat $\beta$ lactamase producing Neisseria gonorrhoeae may have led to changes in the sensitivity patterns of Asian $H$ ducreyi strains. Spectinomycin is an aminocyclitol compound with the same mode of action as, but less toxic than, aminoglycosides; and it has become the preferred drug in many places for the treatment of $\beta$ lactamase producing $N$ gonorrhoeae . It would also be an appropriate agent for use in $\boldsymbol{H}$ ducreyi infections.

Until recently, the peculiarly cohesive nature of $H$ ducreyi, which renders colonies impossible to emulsify, and the inability of the organism to grow in liquid media or on routine sensitivity test agar, have impeded accurate in vitro antimicrobial susceptibility determinations. We developed an ultrasonication method to prepare smooth standardised inocula of $H$ ducreyi strains and used these in an agar dilution technique to determine the minimum inhibitory concentration (MIC) of spectinomycin for a series of strains.

\section{Materials and methods}

\section{HAEMOPHILUS DUCREYI STRAINS}

A total of 66 strains, which had been isolated from cases of classical chancroid and other forms of genital ulceration, were examined: 49 were isolated from patients attending the department of genitourinary medicine, Royal Hallamshire Hospital, Sheffield; four 
were reference strains from the National Collection of Type Cultures, Colindale, London; six were from Ghana (received from Dr RA Ronald), five from the USA (Drs H Hunter-Hansfield and JR Greenwood), one from Canada (Mr I MacLean) and one from Singapore (Dr EH Sng). All were identified according to the methods of Hafiz et al ${ }^{11}$ and were stored in liquid nitrogen at $-130^{\circ} \mathrm{C}$ before testing.

\section{PREPARATION OF INOCULA}

Standardised suspensions for MIC tests were prepared by ultrasonication. Strains were grown on Sheffield medium ${ }^{12}$ for four to five days at $33^{\circ} \mathrm{C}$ in a humidified incubator with an atmosphere of $5 \%$ carbon dioxide. Several colonies were harvested into $2 \mathrm{ml}$ sterile saline and dispersed into smooth suspension by ultrasonic treatment at $6 \mu \mathrm{m}$ for 10 seconds (Ultrasonic Disintegrator, MSE Ltd). This was diluted in saline to give an inoculum suspension of $\simeq 10^{9}$ colony forming units (cfu)/ml by comparison with match opacity tubes (Wellcome Ltd) previously calibrated by having been compared with surface viable counts of sonicated suspensions.

\section{DETERMINATIONS OF MINIMUM INHIBITORY CONCENTRATIONS}

An agar dilution method was used with spectinomycin (Upjohn Ltd). A stock solution containing $320 \mathrm{mg} / 1$ was prepared in distilled water. Doubling dilutions were made and added to Sheffield medium to produce a set of plates containing a range of spectinomycin concentrations from $16-0.007 \mathrm{mg} / \mathrm{l}$. A multipoint inoculator (Denley Instruments Ltd) was used to delivery $0.001 \mathrm{ml}$ inocula $(10=\mathrm{cfu})$ to the surface of the plates containing antibiotic. Sheffield medium without antibiotic was also inoculated as a growth control. All were incubated at $33^{\circ} \mathrm{C}$ in a humidified incubator with an atmosphere of $5 \%$ carbon dioxide. Results were recorded after four days, and the MICs were taken as the lowest concentrations of spectinomycin that prevented growth.

\section{Results}

All 66 strains of $H$ ducreyi were sensitive to spectinomycin. The MIC range was $0.007-16 \mathrm{mg} /$, with $\mathrm{MIC}_{50}$ and $\mathrm{MIC}_{90}$ values of $8 \mathrm{mg} / \mathrm{l}$. The MIC values for the eight $\beta$ lactamase producing strains were slightly lower than the values for all strains, range $0.007-8, \mathrm{MIC}_{50} 0.5$ and $\mathrm{MIC}_{90} 4 \mathrm{mg} / \mathrm{l}$.

\section{Discussion}

The combination of the Sheffield medium for the growth of $H$ ducrey $i$ and the sonication procedure for producing reproducible inocula provided a reliable method for determining the antimicrobial susceptibility of $H$ ducreyi. Our results show that $H$ ducreyi strains from various sources are susceptible to the aminocyclitol antibiotic spectinomycin, which seems to have more reliable activity against this organism than the related aminoglycosides. The MIC values of spectinomycin were well within the range of serum concentrations readily achieved by conventional dose regimens, and this antibiotic may have a useful role in the treatment of chancroid and other infections associated with $H$ ducreyi.

We thank the staff of the department of genitourinary medicine, Sheffield, for clinical support, and colleagues at the National Collection of Type Cultures and elsewhere, who submitted $\boldsymbol{H}$ ducreyi strains for examination. We also thank Miss CJ Cooke and Mrs ME Lee for skilled technical help and Mrs $\mathrm{H}$ Storer for excellent secretarial help. The financial support of Upjohn Ltd is gratefully acknowledged.

\section{References}

1. Hafiz S, Kinghorn GR, McEntegart MG. Haemophilus ducreyi and chancroid. In: Easmon CSF, Jeljazewicz J, eds. Medical microbiology. Vol 4, London: Academic Press, 1984;143-70.

2. Sng EH, Lim AL, Rajan VS, Goh AJ. Characteristics of Haemophilus ducreyi: a study. British Journal of Venereal Diseases 1982;58:239-42.

3. Sturm AW, Zanen HC. Drug of choice for chancroid. Lancet $1983 ; \mathrm{i}: 125$.

4. Asin J. Chancroid. American Journal of Syphilis, Gonorrhea and Venereal Diseases 1952;36:483-7.

5. Marmar JL. The management of resistant chancroid in Vietnam. J Urol 1972;107:807-8.

6. Hart G. Chancroid, donovanosis, lymphogranuloma venereum. Public Health Service Report. Washington DC United States Department of Health Education and Welfare 1975;1-10.

7. Luders G, Braun J, Pietzcker F, Schule D. New therapeutic viewpoints in chancroid. Hautartz 1975;26:35-40.

8. Bardach H, Poitschek CH. Zur Diagnostik und Therapie des Ulcus Molle. Z Hautkr 1979;54:659-67.

9. Morel P, Casin I, Gandiol C, Vallet C, Civatte J. An epidemic of chancroid: 587 cases. Nouv Presse Med 1982;11:655-6.

10. Rajan VS, Sng EH. Streptomycin resistant Haemophilus ducreyi. Lancet 1982;ii:1043.

11. Hafiz S, Kinghorn GR, McEntegart MG. Chancroid in Sheffield. A report of 22 cases diagnosed by isolating Haemophilus ducreyi in a modified medium. British Journal of Venereal Diseases 1981;57:382-6.

12. Hafiz S, Kinghorn GR, McEntegart MG. Sheffield medium for cultivation of Haemophilus ducreyi. British Journal of Venereal Diseases 1984;60: 196-8. 